\title{
Sequencing of mtDNA in Shed Hairs: A Retrospective Analysis of Material from Forensic Cases and a Pre-Screening Method
}

\author{
Martina Nilsson ${ }^{1}$, Stina Norlin $^{1}$ and Marie Allen ${ }^{*}$, \\ ${ }^{I}$ Regional Criminal Investigation Department, Forensic Unit, Stockholm County Police, S-106 75 Stockholm, Sweden \\ ${ }^{2}$ Department of Immunology, Genetics and Pathology, Rudbeck Laboratory, Uppsala University, S-751 85 Uppsala, Sweden
}

\begin{abstract}
In crime scene investigations, shed hairs are one of the most frequently found types of biological evidence material. DNA analysis of hair can be of great significance in forensic investigations, and the sequencing of the hypervariable regions I (HVI) and II (HVII) of the mitochondrial genome has become a useful tool in this field. This paper describes a retrospective evaluation of the potential of sequence analysis of mitochondrial DNA. We examined evidentiary hair and reference samples obtained from 25 criminal investigations conducted over a ten year period and determined the number of matches and exclusions between samples in the investigation. In total, the study includes the results of 129 samples obtained between 1999 and 2008. Analysis resulted in high quality sequence data from most of the evidentiary hairs, allowing comparison to reference samples. On the basis of matches between mitochondrial DNA sequences from evidentiary hairs and those from reference samples, inclusions were obtained in 16 of the 25 cases (64\%). Thus, sequencing of mitochondrial DNA was informative in many cases in this data set. In addition, we conducted an initial evaluation of a strategy for estimating the mitochondrial DNA and nuclear DNA contents of plucked and shed hair samples. The strategy is based on staining both the nuclear DNA and the mitochondria, and may be useful when trying to identify an optimal DNA profiling approach for a given hair sample.
\end{abstract}

Keywords: Mitochondrial DNA, Forensic analysis, Shed hairs, DNA sequencing.

\section{INTRODUCTION}

Shed hairs are frequently found and often used as biological material in forensic investigations. Analysis of DNA in hair is therefore important in criminal investigations [1]. It is estimated that the human scalp holds between 100000 and 150000 hair follicles and that an individual normally sheds up to 100 hairs per day $[2,3]$. Hair has three different stages of growth; (i) an anagen phase (active growth), (ii) a catagen phase (ceasing growth) and (iii) a telogen phase (dormant). Typically, plucked hair is in the anagen phase and can therefore generally provide both nuclear DNA (nDNA) and the more abundant mitochondrial DNA (mtDNA) [4]. In contrast, most hairs collected during crime scene investigations are shed hairs in the telogen phase and contain only limited amounts of nDNA [5]. In fact, more than $90 \%$ of the hairs found at crime scenes have shown to be telogen [6]. As a consequence, analysis of nDNA in shed hairs is challenging or impossible. However, sequencing of mtDNA in shed hairs can provide useful information, even in cases where a long period of time has passed since they were shed $[3,7,8]$.

Routine analysis of mtDNA involves sequencing of the hypervariable regions I (HVI) and II (HVII) in the non-coding D-loop (control region) of the mitochondrial genome $[9,10]$. Due to the high copy number per cell (500-2000 copies), the analysis of mtDNA often has the potential to yield high quality profiles even when the biological material is scarce or highly degraded $[9,11-13]$. It has also been proposed that mtDNA is

\footnotetext{
*Address correspondence to these authors at the Department of Immunology, Genetics and Pathology, Rudbeck Laboratory, Uppsala University, S-751 85 Uppsala, Sweden; Tel: +46 18471 4803; Fax: +46 18471 4808; E-mail: marie.allen@igp.uu.se
}

more resistant to degradation than is nDNA due to the prolonged maintenance of mitochondrial membrane integrity [14]. The maternal inheritance makes mtDNA analysis particularly useful in identifying samples from individuals in the aftermath of events such as mass disasters when neither a direct reference sample nor a sample from a close relative is available. A drawback of mtDNA analysis is the maternal inheritance without recombination resulting in less diversity and a lower discriminatory capabilitity compared to nDNA analysis of multiple markers $[8,9]$. Nevertheless, mtDNA analysis of shed hairs can be a very valuable source of circumstantial evidence in cases where no other types of biological evidence material are available $[15,16]$. Importantly, analysis of mtDNA is equally valuable as nDNA in excluding falsely accused suspects and exonerating falsely convicted individuals.

Mitochondrial DNA analysis of hairs was first used as a source of evidence in a Swedish court in February 1996 [5] and its first use in a US court took place in September of the same year [17]. Since then, it has become more common for mtDNA sequencing to be requested and over 100 such cases have been handled in our laboratory, and the results are occasionally presented as evidence in Swedish courts. In this paper, we summarise the results of a retrospective study comparing mtDNA profiles from evidentiary hair and reference samples obtained in the course of criminal investigations. The results of shed hair analysis from a total of 25 cases were re-examined. The cases involve murders, robberies, rapes, and drug offences. We examined the overall success rate in terms of the number of samples from which high quality sequences were obtained and also the number of cases resulting in inclusion to a reference material. Further, we investigated if any correlation was observed between successful sequence analysis and the colour and length of the hair sample. 
Although most of the hair samples discussed in this study were successfully analysed, some were not, and some may have contained sufficient DNA to permit a nuclear DNA analysis. Therefore, assessing the DNA content of samples before performing a DNA analysis would make it easier to select the most appropriate downstream analysis. We have previously shown that real-time PCR is a powerful method for quantification of mtDNA and nDNA in hair samples prior to sequence analysis [18]. An alternative strategy for nondestructive pre-analysis evaluation of nDNA content in hair samples has recently been described [19]. The approach is based on staining the samples with an nDNA-selective dye (DAPI) and visualising the stained cells with fluorescence microscopy. We hypothesised that it might be possible to extend this method to allow for a simultaneous estimation of the mtDNA content by using an additional dye to stain the mitochondria and tested this hypothesis using the MitoFluor dye.

\section{METHODS}

\section{Study Design}

We examined available data from 25 forensic cases in which mtDNA analyses were performed between 1999 and 2008. These cases were referred to the forensic genetic unit in the Rudbeck laboratory, Uppsala, Sweden from all over the country. Most of these cases involve evidence materials from murders or robberies and a few concern rapes or drug offences. In total, mtDNA analyses were performed on 1065 samples during the investigation of 75 different cases during the period. In this study, we focused exclusively on cases in which hair samples were available in the course of the investigation and in which reference samples were also available for comparative purposes. The reference samples consisted of various types of biological material. The selected cases comprise 73 evidence samples and 56 reference samples. A majority of the reference samples were from individuals of Swedish origin why a Swedish population database as well as the European EMPOP database were used for the statistical evaluation (www.empop.org). A total of 173 comparisons of evidentiary samples to reference material were made. Certain parameters of the evidentiary hair samples were documented, namely: (i) the colour and length of the hair, (ii) whether or not a DNA profile was successfully obtained from the sample, and (iii) the frequency of inclusions and exclusions between the evidentiary sample and the references in each case.

When performing the analyses, all samples were processed individually to prevent contamination at the different stages of analysis. All surfaces and equipment (pipette tips, tubes etc) were exposed to ultraviolet light before extraction and PCR setup and appropriate cleaning with bleach and ethanol was applied. The analysts wore full protective clothing and changed their gloves frequently. All cases were handled individually; no sample from a new case was analysed until the analysis of all samples from the preceding case had been completed. Furthermore, evidentiary samples were always analysed prior to the analysis of the reference samples. Throughout the entire analysis process, the conventional guidelines for mtDNA analyses were followed [20].

\section{Extraction}

Prior to extraction, two centimetres of the proximal segment of the hair shaft was cut with a sterile pair of scissors. The single hair was first rinsed in 1\% SDS and then twice in distilled water. It was then air-dried prior to extraction. The dried hair sample was submerged in $212 \mu \mathrm{L}$ of an extraction solution consisting of 1X PCR buffer (Applied Biosystems, Foster City, $\mathrm{CA}), 240 \mu \mathrm{g} / \mathrm{mL}$ proteinase K (Sigma, St Louis, MO) and $33 \mathrm{mM}$ dithiothreitol (DTT) (Sigma). The hair sample was incubated at $56^{\circ} \mathrm{C}$ for at least two hours or until the hair fragment was disintegrated, and subsequently incubated at $95^{\circ} \mathrm{C}$ for ten minutes to inactivate the proteinase $\mathrm{K}$. Blood samples (references) were extracted using Chelex as described by Walsh et al., [21]. Extraction of DNA from swabs (references) was performed using the Wizard Genomic DNA Extraction Kit (Promega, Madison, WI). For every sample, a blank extraction was included to ensure that no contamination occurred during the process. This extraction control followed the hair extract throughout the analysis. The DNA extracts were stored at $-20^{\circ} \mathrm{C}$ until analysis.

\section{Amplification and Sequence Analysis}

HVI amplification was carried out in a $30 \mu \mathrm{L}$ reaction volume with a final concentration of 1 x PCR Gold Buffer (Applied Biosystems), $1.5 \mathrm{mM} \mathrm{MgCl} 2$ (Applied Biosystems), $0.4 \mu \mathrm{M}$ of the two HVI primers respectively (F15971 and R16410), 0.17 U/ $\mu \mathrm{L}$ Taq Gold (Applied Biosystems), $0.2 \mathrm{mM}$ dNTPs, $0.16 \mathrm{mg} / \mathrm{mL}$ Bovine Serum Albumin (BSA) (Sigma), 8.3\% Glycerol (VWR, West Chester, PA) and $10 \mu \mathrm{L}$ DNA extract. HVII amplification was performed in a $30 \mu \mathrm{L}$ reaction volume with a final concentration of $1.2 \times$ PCR Gold Buffer, 2.4 $\mathrm{mM} \mathrm{MgCl}, 0.2 \mu \mathrm{M}$ of the two HVII primers respectively (F15 and R429), $0.17 \mathrm{U} / \mu \mathrm{L}$ Taq Gold, $0.2 \mathrm{mM}$ dNTPs, $0.17 \mathrm{mg} / \mathrm{mL}$ BSA, 8.3\% Glycerol and $10 \mu \mathrm{L}$ DNA extract. Primers and cycling conditions were as described by Divne et al., [8], with the modification that 38-40 cycles were typically used for the evidentiary hairs. Multiple negative PCR controls were included to detect possible contamination. The amplified material was analysed on a $2 \%$ agarose gel (SeaKem, In vitro, Sweden). For quality assurance, all samples were amplified and sequenced in duplicate. In cases where amplification using this standard protocol failed to give results, amplifications using a larger quantity of the extract, a more dilute or more highly purified sample were attempted. The PCR products were purified using the QIAquick PCR purification kit (Qiagen, GmbH, Germany) or ExoSAP-IT kit (USB, OH). Cycle sequencing of both strands was performed using the BigDye ${ }^{\mathbb{B}}$ Terminator Kit version 3.1 (Applied Biosystems). Primers for sequencing are described by Divne et al., [8]. The samples were analysed using an ABI PRISM 3130 or 3730 Genetic Analyzer ABI (Applied Biosystems). Sequence data was analysed using the Sequencher 4.5 software package (Gene Codes, MI). For mtDNA profiles matching a reference sample a search in relevant population databases were performed to evaluate the evidentiary value.

\section{Fluorescence Microscopy of Hairs}

Hairs were fixated for 15 minutes in $4 \%$ formaldehyde and then washed three times in PBS for 10 to 20 minutes. Mitochondria were stained with MitoFluor ${ }^{\mathrm{TM}}$ Red 589 Dye (Invitrogen, Paisley, UK) for 20 minutes in PBS, with a final dye concentration of $100 \mathrm{nM}$. The dyed hairs were washed three times in PBS for 10 to 20 minutes and then in $0.2 \%$ TritonX for five minutes. The nuclear staining solution was prepared by mixing $1 \mu \mathrm{l}$ of a $5 \mathrm{mg} / \mathrm{ml}$ solution of DAPI (Invitrogen) with 1 $\mathrm{ml}$ PBS. Nuclear staining was performed for five minutes in 
darkness. Hairs were mounted on a microscope slide in $10 \mu 1$ Vectashield (Vectorlabs, CA). Image analyses were performed using a Zeiss fluorescence microscope at 100 to $200 \mathrm{x}$ magnification.

\section{RESULTS}

\section{Retrospective Study of Cases Involving Hairs}

We have evaluated the utility of mtDNA sequencing in forensic investigations by performing a retrospective analysis of shed hair samples collected from 25 different cases over a tenyear period (1999 to 2008). Of the 129 samples from these investigations, $73(57 \%)$ were questioned hairs collected as evidentiary samples and $56(43 \%)$ were known (reference) samples in form of blood (59\%), hair (39\%) or cheek swabs (2\%). The number of questioned hairs collected in each case varied from one to eight and the number of reference samples varied from one to nine. In total, 173 comparisons between questioned and known samples from the same case were performed (Table 1). High quality sequence data was obtained from 66 of the questioned hairs (90\%). Exclusions were based on the observation of nucleotide differences at two or more positions, as recommended by established guidelines [20]. Six of the questioned hair samples failed to yield PCR products or full mtDNA profiles. Furthermore, one sample was interpreted as inconclusive due to mixtures identified at positions 73 and 195 in HVII.

In this small sample set, no correlation was observed between unsuccessful amplification and hair colour or length (Table 2). If the length of the hairs exceeded two centimetres, they were cut in half or a length of at least two centimetres was cut off for extraction. However, amplification and sequencing were successful in cases where the hair fragments were as small as 0.5 centimetres. Both hypervariable regions were successfully amplified in 15 out of 16 samples measuring 2.5 centimetres or less (the lengths of 67 of the evidentiary hair samples were documented). Amplification of the HVI region of one short hair failed; however, the HVII sequence data obtained from this sample was sufficient to exclude three of the four suspects in the relevant case.

The 173 comparisons of evidentiary samples to reference material from the same case resulted in 117 exclusions and 35 inclusions (Table 1). Of all the comparisons attempted, 21 could not be evaluated due to lacking or inconclusive results for seven of the questioned hairs. Thus, a total of 152 successful comparisons (88\%) were performed using samples from the 25 cases. Inclusions were obtained between questioned hair and the reference sample in $23 \%$ of the successful comparisons while exclusions were obtained in $77 \%$. More importantly, at least one inclusion was found in 16 of the 25 cases (64\%). For a majority of the inclusions in our casework routine, no matches are found when searched in the population databases, indicating that the sequence is very rare in the population. For about ten percent of the inclusions, matches are however more frequently found in the population. The mtDNA profile most frequently found is identical to rCRC and belongs to haplogroup $\mathrm{H}$, which is the most common haplogroup among Europeans. Thus, a match with this profile results in a lower evidentiary value. To further illustrate the importance of mtDNA analysis, we describe two cases in more detail.

\section{Case A}

In 1989, a ten-year-old girl was reported missing. Six days later, her body was found and she had been sexually assaulted and murdered. Four evidence hairs were found stuck to the tape on the plastic sack that the victim had been covered with when she was found. Three of the hairs revealed PCR product and none of these matched the victim (reference number 2). One of the evidentiary hairs was only compared to the victim due to the long length of this hair. A first comparison to suspects was done in 2002. Two cousins (reference number 3 and 4), previously convicted for sexual assault, were held in custody in this case. The cousins were maternally released and their common profile did not match any of the samples. In the following years, the police investigated several other suspects. In 2004, an nDNA inclusion between a sperm sample and a suspect (reference number 1) based on LCN (low copy number) analysis was obtained. An mtDNA comparison was then made between the suspect and the hairs, resulting in an inclusion to one of the hairs (comparison 49 in Table 1). This match strengthened the theory that the suspect was involved, not only in the sexual assault, but also in the murder and abduction of the girl. (This case is represented by the entry under Case ID 11 in Table 1). Furthermore, additional biological evidence tied the suspect to another murder in 1989 of a young prostitute. The suspect was sentenced to lifetime imprisonment on the basis of the DNA analyses as well as multiple additional lines of evidence. This investigation demonstrates how different types of genetic analyses can be relevant and contribute with informative inclusions, exclusions as well as links to several crimes.

\section{Case B}

In a drug offence case in 2008, in which almost ten kilograms of heroin were confiscated, a total of seven shed hairs were collected. The hairs were collected at different locations and subjected to mtDNA analysis; it was found that three hairs from three different locations had identical mtDNA profiles. The three matching hairs were found on confiscated material collected from (i) the car in which the narcotics were suspected to have been transported, (ii) the bag in which the narcotics were found, and (iii) a baking tray from an apartment. In this case, a link between evidence collected at different locations was requested, why no reference samples were submitted. When the case was brought to trial, this evidence was used in court to support the theory that the suspects were guilty of acting as couriers, transporting and delivering the narcotics. One of the accused was sentenced to ten years in prison, while another was sentenced to ten years in prison in addition to deportation. The convictions were obtained on the basis of the DNA analyses along with other circumstantial evidence. (Data from this case was not included in this study because of the absence of reference samples from the suspects).

\section{Visualisation of nDNA and mtDNA in Hairs}

The DNA content of hairs is highly variable, and depends on the growth phase the hair was in when it was shed, intra- and interindividual variation, the amount of time that has elapsed since shedding, and whether the hair was naturally shed or plucked [18]. Moreover, if the hair was plucked or pulled, there may be a variable amount of soft tissue attached to the root. Therefore, knowledge of the cell and DNA content is valuable 
Table 1. Results of the 173 Comparisons of Material from 25 Cases

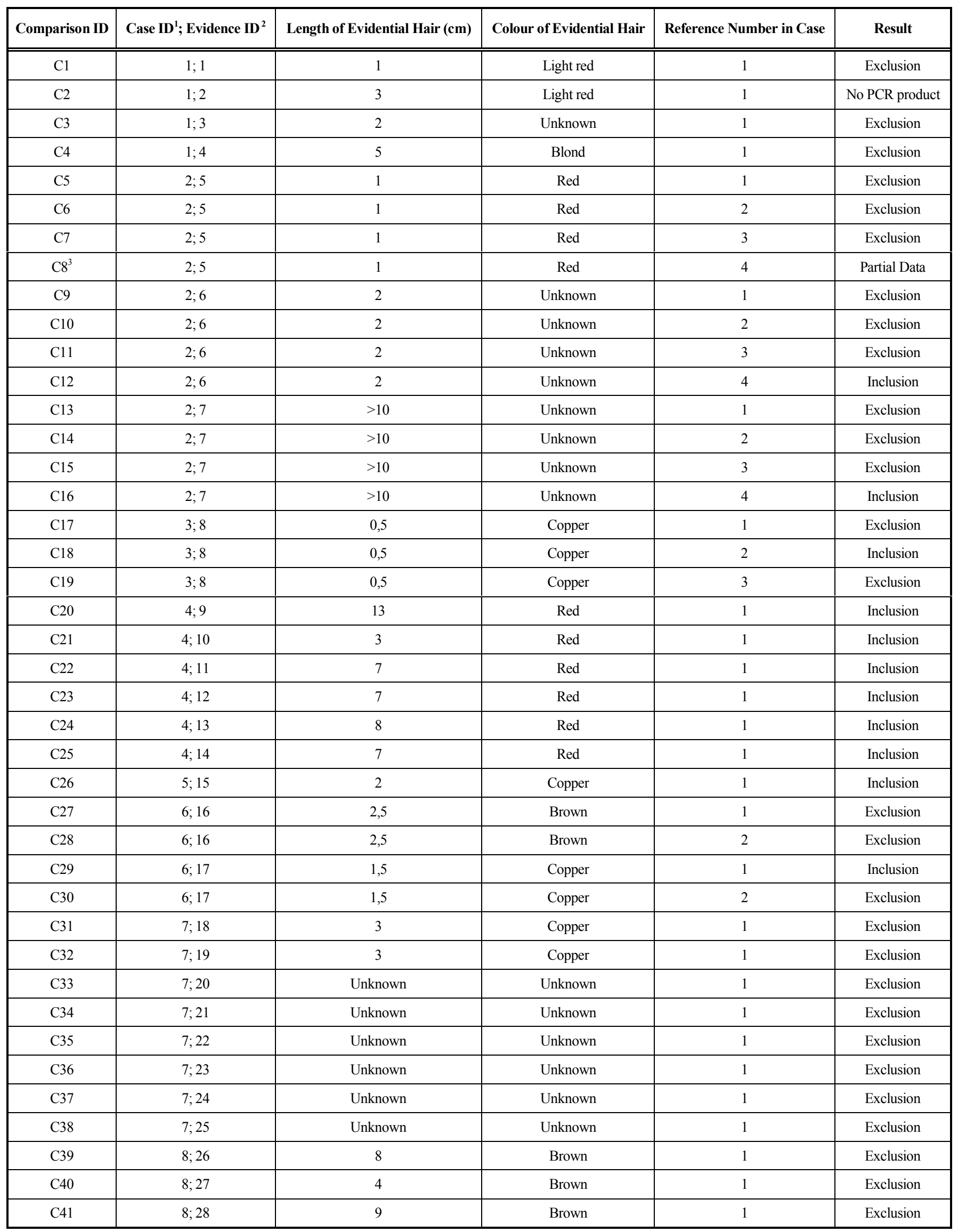




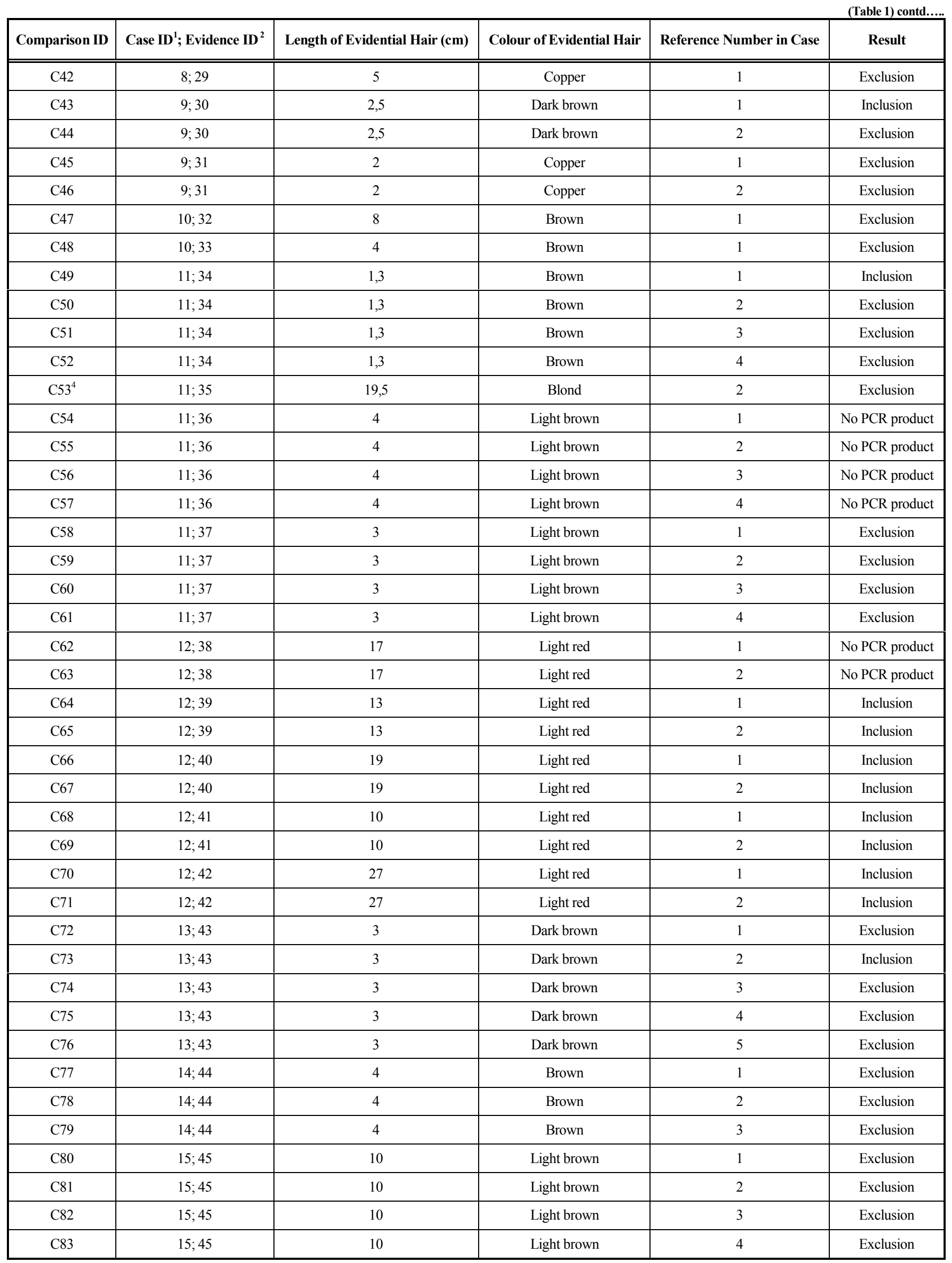




\begin{tabular}{|c|c|c|c|c|c|}
\hline Comparison ID & Case ID $^{1}$; Evidence ID $^{2}$ & Length of Evidential Hair (cm) & Colour of Evidential Hair & Reference Number in Case & Result \\
\hline $\mathrm{C} 84$ & $15 ; 45$ & 10 & Light brown & 5 & Exclusion \\
\hline $\mathrm{C} 85$ & $15 ; 45$ & 10 & Light brown & 6 & Exclusion \\
\hline $\mathrm{C} 86$ & $15 ; 45$ & 10 & Light brown & 7 & Exclusion \\
\hline $\mathrm{C} 87$ & $15 ; 45$ & 10 & Light brown & 8 & Exclusion \\
\hline $\mathrm{C} 88$ & 15,45 & 10 & Light brown & 9 & Exclusion \\
\hline C89 & $15 ; 46$ & 6,5 & Brown & 1 & Exclusion \\
\hline C90 & $15 ; 46$ & 6,5 & Brown & 2 & Exclusion \\
\hline C91 & $15 ; 46$ & 6,5 & Brown & 3 & Exclusion \\
\hline C92 & $15 ; 46$ & 6,5 & Brown & 4 & Exclusion \\
\hline C93 & $15 ; 46$ & 6,5 & Brown & 5 & Exclusion \\
\hline C94 & $15 ; 46$ & 6,5 & Brown & 6 & Exclusion \\
\hline C95 & $15 ; 46$ & 6,5 & Brown & 7 & Exclusion \\
\hline C96 & $15 ; 46$ & 6,5 & Brown & 8 & Exclusion \\
\hline C97 & $15 ; 46$ & 6,5 & Brown & 9 & Exclusion \\
\hline C98 & $15 ; 47$ & 32 & Brown & 1 & No PCR product \\
\hline C99 & $15 ; 47$ & 32 & Brown & 2 & No $P C R$ product \\
\hline C100 & $15 ; 47$ & 32 & Brown & 3 & No $P C R$ product \\
\hline C101 & $15 ; 47$ & 32 & Brown & 4 & No PCR product \\
\hline C102 & $15 ; 47$ & 32 & Brown & 5 & No PCR product \\
\hline C103 & $15 ; 47$ & 32 & Brown & 6 & No PCR product \\
\hline C104 & $15 ; 47$ & 32 & Brown & 7 & No PCR product \\
\hline C105 & $15 ; 47$ & 32 & Brown & 8 & No $\mathrm{PCR}$ product \\
\hline C106 & $15 ; 47$ & 32 & Brown & 9 & No PCR product \\
\hline C107 & $15 ; 48$ & 20 & Blond & 1 & Exclusion \\
\hline C108 & $15 ; 48$ & 20 & Blond & 2 & Exclusion \\
\hline C109 & $15 ; 48$ & 20 & Blond & 3 & Exclusion \\
\hline $\mathrm{C} 110$ & $15 ; 48$ & 20 & Blond & 4 & Exclusion \\
\hline C111 & $15 ; 48$ & 20 & Blond & 5 & Exclusion \\
\hline $\mathrm{C} 112$ & $15 ; 48$ & 20 & Blond & 6 & Exclusion \\
\hline C113 & $15 ; 48$ & 20 & Blond & 7 & Exclusion \\
\hline $\mathrm{C} 114$ & $15 ; 48$ & 20 & Blond & 8 & Inclusion \\
\hline C115 & $15 ; 48$ & 20 & Blond & 9 & Exclusion \\
\hline C116 & $15 ; 49$ & 24 & Copper & 1 & Exclusion \\
\hline C117 & $15 ; 49$ & 24 & Copper & 2 & Exclusion \\
\hline C118 & $15 ; 49$ & 24 & Copper & 3 & Exclusion \\
\hline C119 & $15 ; 49$ & 24 & Copper & 4 & Exclusion \\
\hline $\mathrm{C} 120$ & $15 ; 49$ & 24 & Copper & 5 & Exclusion \\
\hline $\mathrm{C} 121$ & $15 ; 49$ & 24 & Copper & 6 & Exclusion \\
\hline $\mathrm{C} 122$ & $15 ; 49$ & 24 & Copper & 7 & Exclusion \\
\hline $\mathrm{C} 123$ & $15 ; 49$ & 24 & Copper & 8 & Exclusion \\
\hline $\mathrm{C} 124$ & $15 ; 49$ & 24 & Copper & 9 & Exclusion \\
\hline $\mathrm{C} 125$ & $15 ; 50$ & 5 & Brown & 1 & Exclusion \\
\hline
\end{tabular}




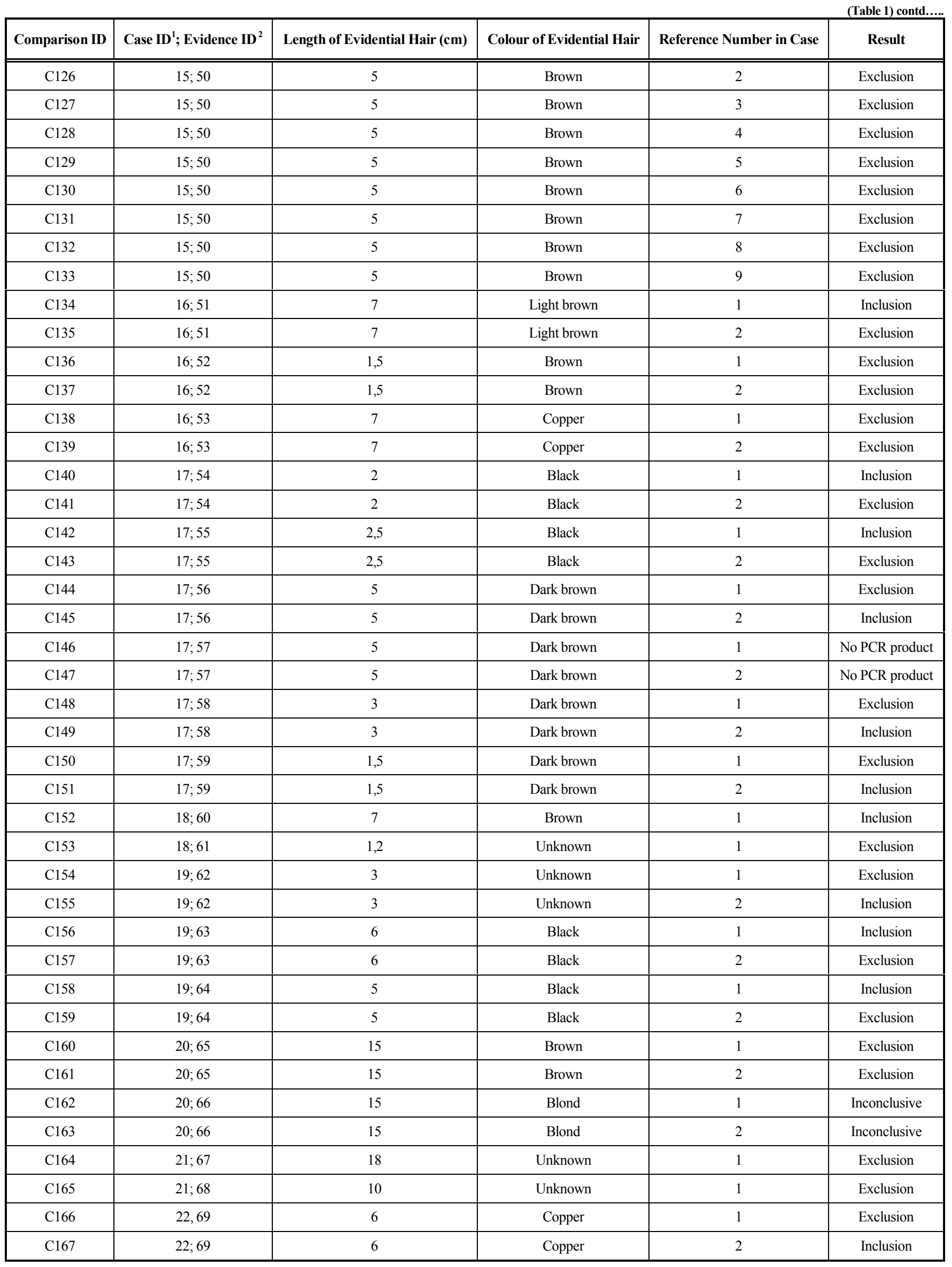


(Table 1) contd.....

\begin{tabular}{|c|c|c|c|c|c|}
\hline Comparison ID & Case ID $^{1}$; Evidence ID ${ }^{2}$ & Length of Evidential Hair (cm) & Colour of Evidential Hair & Reference Number in Case & Result \\
\hline $\mathrm{C} 168$ & $23 ; 70$ & 9 & Blond & 1 & Exclusion \\
\hline $\mathrm{C} 169$ & $23 ; 70$ & 9 & Blond & 2 & Inclusion \\
\hline $\mathrm{C} 170$ & $23 ; 71$ & 3 & Dark & 1 & Exclusion \\
\hline $\mathrm{C} 171$ & $23 ; 71$ & 3 & Dark & 2 & Exclusion \\
\hline $\mathrm{C} 172$ & $24 ; 72$ & 3 & Light brown & 1 & Exclusion \\
\hline $\mathrm{C} 173$ & $25 ; 73$ & 4 & Dark brown & 1 & Exclusion \\
\hline
\end{tabular}

Table 2. Characteristics of the Six Evidential Hair Samples that Failed to Amplify

\begin{tabular}{|c|c|c|}
\hline $\begin{array}{c}\text { Length of Questioned } \\
\text { Hair Sample (cm) }\end{array}$ & $\begin{array}{c}\text { Colour of Questioned } \\
\text { Hair Sample }\end{array}$ & Evidence ID \\
\hline \hline 3 & Light red & 2 \\
\hline 1 & Red & 36 \\
\hline 4 & Light brown & 38 \\
\hline 17 & Light red & 47 \\
\hline 32 & Brown & 57 \\
\hline 5 & Dark brown & \\
\hline
\end{tabular}

in selection of the most appropriate DNA analysis. In order to have an individual strategy for each sample and their specific DNA content, we have utilised DAPI staining and fluorescence microscopy of nDNA previously described by Bourguignon et al., [19]. In addition, to evaluate the mtDNA content of hairs, we stained them with the mitochondrion-specific dye MitoFluor Red. In an initial study shed and plucked hairs were stained with both dyes and analysed by fluorescence microscopy. Both mitochondria and nuclei were visible in the hairs (Fig. 1). Interestingly, in shed hair, most of the stained mitochondria were located in the fibrous sheath, the cortex and the shaft. On the other hand, most of the stained nuclei were localised in the inner and outer root sheath. In plucked hair, the majority of the stained nuclei were located in the soft tissue attached to the shaft. The staining of hairs show that it is possible to visualise both mtDNA and nDNA simultaneously to aid in a subsequent choice of downstream analysis (Fig. 1).

\section{DISCUSSION}

In this study, we examined the use of shed hairs and as a source of evidence in forensic investigations. Sequencing of mtDNA gave high quality data from $90 \%$ of the samples in our retrospective dataset. A total of 173 comparisons were performed between unknown and reference samples from the same case, resulting in inclusions associating at least one evidence sample with a suspect in more than half of the 25 cases (64\%). A majority of the inclusions (13/16 cases) were between a questioned sample and a suspect and therefore likely to be of weight in the investigation. However, it is important to keep in mind that also exclusions can provide highly important information. Moreover, sequence data were obtained in cases where the hair was as short as five millimetres, demonstrating that even short or fragmented hairs can be analysed successfully. Thus, in many of the cases examined, the analysis resulted in either inclusion or exclusion of a suspect, demonstrating the benefits of mtDNA analysis of shed hair as forensic evidence.

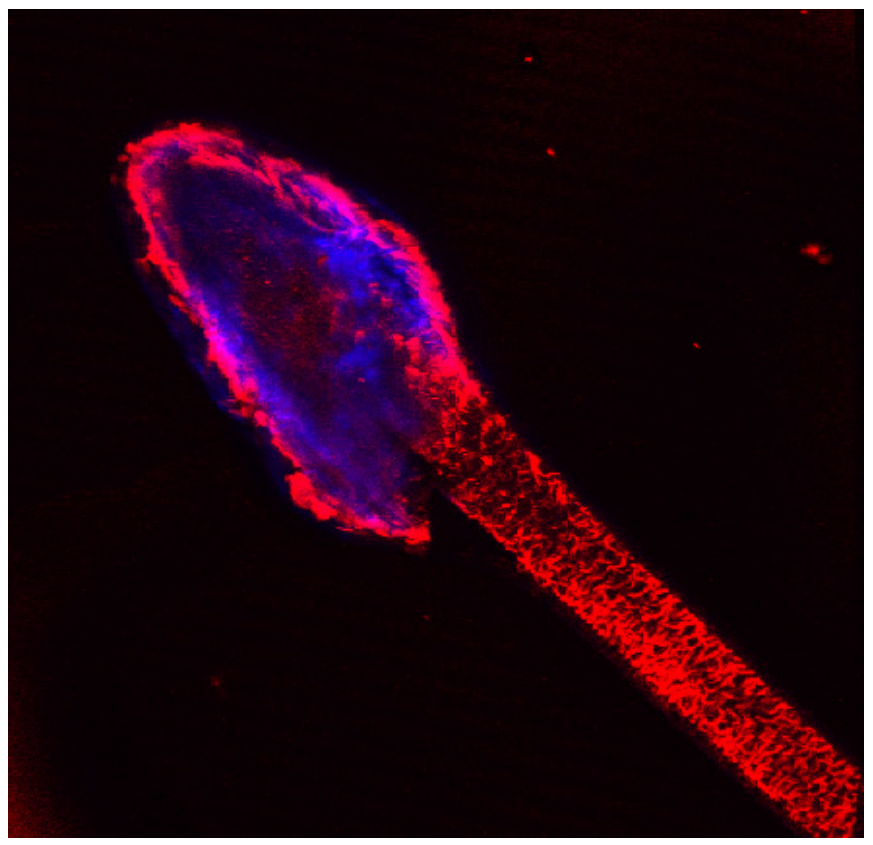

Fig. (1). A shed hair stained with DAPI and MitoFluor. Red color display the mitochondria and blue colour display the nuclear DNA.

Various kinds of biological evidence material can be collected during an investigation, including saliva, blood, semen, epithelial cells, teeth, bone or hair. Teeth, bone and hair have the advantage of having high sample integrity, which allows removal of external contaminants (e.g. with bleach). In a previous study, hair was shown to be resistant to penetration by contaminating DNA molecules and the hydrophobic and impermeable structure makes it easy to remove contaminating DNA from its surface by mechanical means [14, 22]. Moreover, hairs have the advantage that humans frequently shed telogen hairs that can be collected at a crime scene and used as 
evidence. Disadvantages, on the other hand, are that hairs have low amounts of DNA and can be easily transferred between locations unintentionally. Nevertheless, mtDNA analysis can be useful when the biological evidence materials gathered contain limited amounts of nDNA.

There are several factors that influence the likelihood of achieving a successful mtDNA profile, such as the extraction protocol used, the presence of inhibitors, the growth phase of the hair, the age of the sample, and the extent to which it has been degraded. In particular, the method of extraction used has proven to be a critical factor in obtaining a high success rate in DNA typing. If the hair is totally dissolved and the disulphide bonds within the hair are broken an efficient amplification of DNA in hair is possible. Large variations are seen with some types of hair being resistant to proteinase $\mathrm{K}$ but that lyses well when dithiothreitol (DTT) is added to the extraction solution [5, 6, 23-25]. Previously it has been suggested that dark, highly melanised hairs inhibit PCR [26]. Conversely, other authors have reported that dark hair contains abundant mtDNA and does not inhibit PCR [27]. Inhibitory effects can be efficiently countered by using Bovine Serum Albumin (BSA) as an additive in the PCR reaction mixture [28].

The growth phase of the analysed hair has a substantial effect on its DNA content. We have previously shown using real-time PCR that the DNA content of the roots of shed (telogen) hairs differs significantly from that of plucked (anagen/catagen) hairs. The average mtDNA content of the first centimetre of shed hairs (45.700 mtDNA copies) was found to be approximately 77 times lower than that of plucked hairs (3.513.800 mtDNA copies). Moreover, it was found that the DNA content of the hair decreased with increasing distance from the root. In the more distal segments of the hair, the difference in DNA content between shed and plucked hairs was small [18].

Degradation of DNA is a common problem in forensic investigations, and even more challenging in studies of ancient DNA. Despite this, we have previously successfully performed mtDNA analysis in cold case investigations, examining hairs shed over 20 years ago. Furthermore, DNA analyses have been successfully conducted on hairs collected from mammoths [29, 30], Inuit mummies [31], and well-known individuals such as Copernicus [32] and Sir Isaac Newton [33] (spanning from 50.000 to 270 years in age). The possibility to analyse DNA from older specimens decreases with time, primarily due to degradation but also as a result of post-mortem damage [34]. Consequently, most ancient samples are only amenable to mtDNA analysis.

In forensic casework investigations, analysis of $\mathrm{nDNA}$ is preferred because of its very high evidence value. In order to allow or optimise nDNA analysis of challenging samples, reduced-size STR assays have been developed that can be applied in the analysis of shed hairs $[6,23,24]$. In a previous study based on 11 STR loci, analysis of telogen hair roots from forensic cases resulted in full DNA profiles for $65 \%$ of the sampled hairs [6]. Moreover, an assay utilising six miniSTR loci revealed complete DNA profiles for $41 \%$ of hairs found at crime scenes [24]. In addition to its higher evidence value a significant advantage of nDNA analysis is that the profiles obtained can be compared with those in national databases.

We have previously shown that the DNA content of hair decreases gradually as one gets further from the root and that there are large inter- and intra-individual differences in the hair DNA contents [18]. Thus, significant variation in DNA contents are observed even when the samples are identical in terms of their growth phase, whether they were plucked or shed, the distance from the root at which they were obtained, and time since shedding/sampling. Because of this high degree of variation, a pre-screening tool for evaluating the DNA content in hairs prior to sequence analysis would facilitate the selection of an appropriate assay for further genetic analysis. The use of a pre-screening method based on the visualisation of nDNA using DAPI staining in conjunction with fluorescence microscopy has been suggested as an alternative to real-time PCR assays [19]. This strategy has the advantage that it does not consume the sample and does not interfere with subsequent PCR analysis. In this study, Bourguignon et al., estimated the number of nDNA copies in a large number of hair samples and found that 2672 of the 3242 telogen roots examined (i.e. more than $80 \%$ of them) contained no visible fluorescent nuclei [19]. We have made an addition to this DAPI staining strategy, in which we used the mitochondrion-selective dye MitoFluor to visualise both nDNA and mtDNA simultaneously. Our results suggest that this approach may be useful as a screening, especially for evaluating the mtDNA content of hairs that lack visible nuclei. Although the initial results obtained with this dual staining technique are promising, further studies will be needed in order to develop it into a routinely applicable method. However, it is important to use a dye that are not selectively staining mitochondria in live cells in order to be useful in a forensic setting.

An interesting observation in our previous study using realtime PCR quantification is that shed hairs seem to contain a larger proportion of mtDNA than would be expected on the basis of their nDNA content. On average, shed hairs contained $45.700 \mathrm{mtDNA}$ copies but no nDNA copies [18]. This may be because mtDNA is more efficiently protected by keratinisation than is nDNA, rendering it less susceptible to degradation by bacteria and shielding it from water exposure that would result in post-mortem damage, as suggested by Gilbert et al., [22].

The hair samples that could not be amplified in this study were very different to one-another in terms of their length and colour. Of the evidence hair samples that were successfully amplified, $24 \%$ were 2.5 centimetres in length or less, while some of the samples that could not be amplified were much longer. Thus, despite the small sample set examined, our results suggest that parameters such as the length and colour of the hair sample have little impact on the likelihood of successful DNA amplification. It is perhaps more likely that the samples that could not be analysed were old and degraded, or had been otherwise damaged. Alternatively, they may have been cut or torn hairs containing only distal hair segments, which have lower mtDNA amounts further from the root [18].

In conclusion, the sequencing of mtDNA in hair samples is a powerful technique for including and excluding individuals. Using this method, matches between evidentiary and reference samples were obtained in more than half of the cases examined in this study. Moreover, with further research and development, the utility and power of mtDNA analyses could be increased.

\section{ACKNOWLEDGEMENT}

This work was supported by a grant from the Kjell and Märta Beijer foundation. Dr. Lucia Cavelier and Marie Sevov kindly helped us with staining and microscopy of hairs. 


\section{CONFLICT OF INTEREST}

Declared none.

\section{REFERENCES}

[1] Higuchi, R.; von Beroldingen, C. H.; Sensabaugh, G. F.; Erlich, H. A. DNA typing from single hairs. Nature, 1988, 332 (6164), 543546

[2] Bedocs, L.A.; Bruckner, A.L. Adolescent hair loss. Curr. Opin. Pediatr., 2008, 20 (4), 431-435.

[3] Pfeiffer, H.; Brinkmann, B.; Huhne, J.; Rolf, B.; Morris, A.A.; Steighner, R.; Holland, M.M.; Forster, P. Expanding the forensic German mitochondrial DNA control region database: genetic diversity as a function of sample size and microgeography. Int. $J$. Legal. Med., 1999, 112 (5), 291-298.

[4] Roberts, K.A.; Calloway, C. Mitochondrial DNA amplification success rate as a function of hair morphology. J. For. Sci., 2007, 52 (1), 40-47.

[5] Allen, M.; Engstrom, A.S.; Meyers, S.; Handt, O.; Saldeen, T.; von Haeseler, A.; Paabo, S.; Gyllensten, U. Mitochondrial DNA sequencing of shed hairs and saliva on robbery caps: sensitivity and matching probabilities. J. For. Sci., 1998, 43 (3), 453-464.

[6] Bender, K.; Schneider, P. M. Validation and casework testing of the BioPlex-11 for STR typing of telogen hair roots. For. Sci. Int., 2006, 161 (1), 52-59.

[7] Robin, E.D.; Wong, R. Mitochondrial DNA molecules and virtual number of mitochondria per cell in mammalian cells. J. Cell. Physiol., 1988, 136 (3), 507-513.

[8] Divne, A.M.; Nilsson, M.; Calloway, C.; Reynolds, R.; Erlich, H.; Allen, M. Forensic casework analysis using the HVI/HVII mtDNA linear array assay. J. For. Sci., 2005, 50 (3), 548-554.

[9] Budowle, B.; Allard, M.W.; Wilson, M.R.; Chakraborty, R. Forensics and mitochondrial DNA: applications, debates, and foundations. Annu. Rev. Genomics Hum. Genet., 2003, 4, 119-141.

[10] Primorac, D.; Schanfield, M.S. Application of forensic DNA testing in the legal system. Croat. Med. J., 2000, 41 (1), 32-46.

[11] Dimo-Simonin, N.; Grange, F.; Taroni, F.; Brandt-Casadevall, C.; Mangin, P. Forensic evaluation of mtDNA in a population from south west Switzerland. Int. J. Legal. Med., 2000, 113 (2), 89-97.

[12] Divne, A.M.; Allen, M. A DNA microarray system for forensic SNP analysis. For. Sci. Int., 2005, 154 (2-3), 111-121.

[13] Salas, A.; Lareu, M.V.; Carracedo, A. Heteroplasmy in mtDNA and the weight of evidence in forensic mtDNA analysis: a case report. Int. J. Legal. Med., 2001, 114 (3), 186-190.

[14] Gilbert, M.T.; Menez, L.; Janaway, R.C.; Tobin, D.J.; Cooper, A.; Wilson, A.S. Resistance of degraded hair shafts to contaminant DNA. For. Sci. Int., 2006, 156 (2-3), 208-212.

[15] Melton, T.; Nelson, K. Forensic mitochondrial DNA analysis: two years of commercial casework experience in the United States. Croat. Med.J., 2001, 42 (3), 298-303.

[16] Nelson, K.; Melton, T. Forensic mitochondrial DNA analysis of 116 casework skeletal samples. J. For. Sci., 2007, 52 (3), 557-561.

[17] Davis, C.L. Mitochondrial DNA: State of Tennessee v. Paul Ware. Profiles in DNA, 1998, 1(3), 6-7.

[18] Andreasson, H.; Nilsson, M.; Budowle, B.; Lundberg, H.; Allen, M. Nuclear and mitochondrial DNA quantification of various forensic materials. For. Sci. Int., 2006, 164 (1), 56-64.

[19] Bourguignon, L.; Hoste, B.; Boonen, T.; Vits, K.; Hubrecht, F. A fluorescent microscopy-screening test for efficient STR-typing of telogen hair roots. For. Sci. Int. Genet., 2008, 3 (1), 27-31.
[20] Bar, W.; Brinkmann, B.; Budowle, B.; Carracedo, A.; Gill, P.; Holland, M.; Lincoln, P.J.; Mayr, W.; Morling, N.; Olaisen, B.; Schneider, P.M.; Tully, G.; Wilson, M. DNA Commission of the International Society for Forensic Genetics: guidelines for mitochondrial DNA typing. Int. J. Legal. Med., 2000, 113 (4), 193196.

[21] Walsh, P.S.; Metzger, D.A.; Higuchi, R. Chelex 100 as a medium for simple extraction of DNA for PCR-based typing from forensic material. Biotechniques, 1991, 10 (4), 506-513.

[22] Gilbert, M.T.; Tomsho, L.P.; Rendulic, S.; Packard, M.; Drautz, D.I.; Sher, A.; Tikhonov, A.; Dalen, L.; Kuznetsova, T.; Kosintsev, P.; Campos, P.F.; Higham, T.; Collins, M.J.; Wilson, A.S.; Shidlovskiy, F.; Buigues, B.; Ericson, P.G.; Germonpre, M.; Gotherstrom, A.; Iacumin, P.; Nikolaev, V.; Nowak-Kemp, M.; Willerslev, E.; Knight, J.R.; Irzyk, G.P.; Perbost, C.S.; Fredrikson, K.M.; Harkins, T.T.; Sheridan, S.; Miller, W.; Schuster, S.C. Whole-genome shotgun sequencing of mitochondria from ancient hair shafts. Sci., 2007, 317 (5846), 1927-1930.

[23] Hellmann, A.; Rohleder, U.; Schmitter, H.; Wittig, M. STR typing of human telogen hairs--a new approach. Int. J. Legal. Med., 2001 , 114 (4-5), 269-273.

[24] Muller, K.; Klein, R.; Miltner, E.; Wiegand, P. Improved STR typing of telogen hair root and hair shaft DNA. Electrophoresis, 2007, 28 (16), 2835-2842.

[25] Vigilant, L. An evaluation of techniques for the extraction and amplification of DNA from naturally shed hairs. Biol. Chem., 1999, 380 (11), 1329-1331.

[26] Yoshii, T.; Tamura, K.; Taniguchi, T.; Akiyama, K.; Ishiyama, I. Water-soluble eumelanin as a PCR-inhibitor and a simple method for its removal]. Nihon. Hoigaku. Zasshi., 1993, 47 (4), 323-329.

[27] Melton, T.; Dimick, G.; Higgins, B.; Lindstrom, L.; Nelson, K. Forensic mitochondrial DNA analysis of 691 casework hairs. $J$. For. Sci., 2005, 50 (1), 73-80.

[28] Giambernardi, T.A.; Rodeck, U.; Klebe, R.J. Bovine serum albumin reverses inhibition of RT-PCR by melanin. Biotechniques, 1998, 25 (4), 564-566.

[29] Krause, J.; Dear, P.H.; Pollack, J.L.; Slatkin, M.; Spriggs, H.; Barnes, I.; Lister, A.M.; Ebersberger, I.; Paabo, S.; Hofreiter, M. Multiplex amplification of the mammoth mitochondrial genome and the evolution of Elephantidae. Nature, 2006, 439 (7077), 724727.

[30] Poinar, H.N.; Schwarz, C.; Qi, J.; Shapiro, B.; Macphee, R.D.; Buigues, B.; Tikhonov, A.; Huson, D.H.; Tomsho, L.P.; Auch, A.; Rampp, M.; Miller, W.; Schuster, S.C. Metagenomics to paleogenomics: large-scale sequencing of mammoth DNA. Sci., 2006, 311 (5759), 392-394.

[31] Gilbert, M.T.; Djurhuus, D.; Melchior, L.; Lynnerup, N.; Worobey, M.; Wilson, A.S.; Andreasen, C.; Dissing, J. mtDNA from hair and nail clarifies the genetic relationship of the 15th century Qilakitsoq Inuit mummies. Am. J. Phys. Anthropol., 2007, 133 (2), 847-853.

[32] Bogdanowicz, W.; Allen, M.; Branicki, W.; Lembring, M.; Gajewska, M.; Kupiec, T. Genetic identification of putative remains of the famous astronomer Nicolaus Copernicus. Proc. Natl. Acad. Sci. U. S. A., 2009, 106 (30), 12279-12282.

[33] Gilbert, M.T.; Wilson, A.S.; Bunce, M.; Hansen, A.J.; Willerslev, E.; Shapiro, B.; Higham, T.F.; Richards, M.P.; O'Connell, T.C.; Tobin, D.J.; Janaway, R.C.; Cooper, A. Ancient mitochondrial DNA from hair. Curr. Biol., 2004, 14 (12), R463-R464.

[34] Gilbert, M.T.; Willerslev, E.; Hansen, A.J.; Barnes, I.; Rudbeck, L.; Lynnerup, N.; Cooper, A. Distribution patterns of postmortem damage in human mitochondrial DNA. Am. J. Hum. Genet., 2003, $72(1), 32-47$. 